\title{
Maternal and Neonatal Factors Influencing Preterm Birth and Low Birth Weight in Oman: A Hospital Based Study
}

\author{
M. Mazharul Islam ${ }^{1, *}$, Khalid Al-Thihli ${ }^{2}$ and Mohamed Abdellatif ${ }^{3}$ \\ ${ }^{1}$ Department of Mathematics and Statistics, Sultan Qaboos University, Oman \\ ${ }^{2}$ Department of Genetics, Genetics and Developmental Medicine Clinic, Sultan Qaboos University, Oman \\ ${ }^{3}$ Department of Child Health, Neonatal Unit, Sultan Qaboos University, Oman
}

\begin{abstract}
Background: Preterm births (PTB) and low birth weight (LBW) - the two distinct adverse pregnancy outcomes are the major determinants of perinatal survival and development. The purpose of this study was to determine the incidence of LBW and PTB and identify the maternal and neonatal risk factors influencing them.

Methods: Data for the study come from a cross-sectional retrospective study conducted at the maternity ward of Sultan Qaboos University Hospital (SQUH) in Oman during the period between November 2011 and February 2012. Data on 534 singleton live births that occurred during the study period were extracted from hospital record. Descriptive statistics, bivariate analysis and multivariate logistic regression model were used for data analysis.

Results: The incidence of PTB and LBW were observed to be $9.7 \%$ and $13.7 \%$ respectively. Half $(51.8 \%)$ of the LBW babies were PTB and $48.2 \%$ of the LBW babies were of term births. Differences and similarities were noted for the risk profile for PTB and LBW. Risk factors specific to PTB were maternal age, previous pregnancy loss, and infant's length, while birth interval, maternal weight and BMI during pregnancy, and gestational age were the risk factors unique to LBW. ANC visit, infant's gender, Apgar score, and head circumference of infants were the common significant risk factors influencing both LBW and PTB.

Conclusions: The incidence of PTB and LBW are moderately high in Oman. They are associated with different risk factors. A greater understanding and modification of identified risk factors would help reduce the incidence of PTB and LBW in Oman.
\end{abstract}

Keywords: Birth weight, Low birth weight, Preterm birth, Incidence, Risk factor, Consanguinity, Oman.

\section{INTRODUCTION}

Preterm birth (PTB) and low birth weight (LBW) defined, respectively, as birth occurring before 37 weeks of gestation and weight at birth $<2,500 \mathrm{~g}$ [1], are widely acknowledged as major determinants of perinatal survival, infant morbidity and mortality as well as risk factors for development of disabilities and illnesses in future [2-7]. Epidemiological studies have shown that LBW and PTB are linked to adverse health outcomes in early and later life [2, 3, 5]. Among the adverse health outcomes, delays in cognitive and behavioral development [8], growth retardation and neurological problems in childhood [2], as well as chronic diseases such as hypertension, stroke, coronary heart disease and related disorders and diabetes in adulthood are important [9, 10]. PTBs are the second most common cause of death after pneumonia in children under 5 years old and are estimated to be responsible for $35 \%$ of the world's 3.1 million annual neonatal deaths [11, 12]. LBW babies are 20 times more likely to die in their first year of life

*Address correspondence to this author at the Department of Mathematics and Statistics, Sultan Qaboos University, P.O. Box 36, Alkhoudh 123, Sultanate of Oman; Tel: (968) 98264437; Fax: (968) 24141490;

E-mails:mmazhar.islam@yahoo.com, mislam@squ.edu.om

E-ISSN: 1929-4247/13 than normal weight ( $\geq 2500 \mathrm{~g}$ ) babies [5]. PTBs account for three-fourth $(75 \%)$ of perinatal mortality globally [5, 7]. Although, about 20 million (15\%) of all live births worldwide are LBW, it accounts for $60-80 \%$ of all neonatal deaths $[5,7,13]$. It has been observed that $96 \%$ of LBW infants live in developing countries, with nearly sixty percent (59\%) live in South-Asia and $27 \%$ in sub-Saharan Africa [5]. The incidence of LBW in developing countries (17\%) is more than double the incidence in developed regions (7\%) [5]. Thus, low birth weight remains as a significant public health problem more in developing countries than developed countries, and it has emerged as the central focus of infant health policy and as a leading indicator of infant health and wellbeing. A reduction of at least one third of the incidence of LBW is one of the major goals of the 1990 World Summit for Children [14]. The reduction of LBW is also related to the Millennium Development Goal (MDG) for reducing child mortality.

Among other factors, birth weight is strongly influenced by preterm delivery or restricted fetal growth (i.e. term birth with LBW), called 'intra-uterine growth retardation' (IUGR) [3, 15, 16]. These two types of LBW should be treated separately as they are linked to different risks of mortality and morbidity as well as to different etiology, requiring different preventive

๑) 2013 Lifescience Global 
strategies $[17,18]$. On the other hand, a substantial proportion of infants are born prematurely but their birth weights is appropriate for gestational age, and therefore, not usually considered as a risk group. In a study, Frisbie et al. [19] observed higher infant mortality rate among the normal weight preterm births than the normal weight full term births and concluded that normal weight preterm births should be considered as separate risk group in LBW analysis.

The duration of gestation, fetal growth, birth weight and future health are all affected by many factors relating to the infant, the mother and the physical environment or the genetics background [5]. The risk factors of PTB and LBW include maternal health and risky health behavior, inadequate antenatal care, psychosocial stress, low maternal body mass index, poor nutrition, diseases, diet and lifestyle during pregnancy, socio-economic and demographic characteristics of mother, sex and parity of the baby, genetic factors and environmental pollution [5, 17, 18]. Studies have indicated that for the same gestational age, girls weigh less than boys, twins weigh less and born before 37 weeks of gestation than singletons; firstborn infants are lighter and have higher chances of being born prematurely compared with births of higher order [5, 20,21]. The physique, height and weight of the mother before conception also affect the weight and gestational age of a baby [22, 23]. Maternal age is an important determinant of LBW and PTB. Teenage mothers and those aged 35 or more have higher chances of giving birth to lighter or premature babies $[20,24]$. Early antenatal care and healthy lifestyle of the mother (diet and habits) are also important determinants of LBW and PTB [25]. Many studies have shown that smoking, drug abuse and alcohol consumption contribute to a high incidence of adverse pregnancy outcomes [26, 27].

Although the pattern of risk factors for PTB and LBW may be similar among populations, the relative contribution of each factor may vary from one setting to another $[3,28,29]$. The influence of various risk factors for PTB and LBW in developing countries is different from that observed in developed countries. It is, therefore, important to identify population-specific risk factors for PTB and LBW, so that appropriate policies could be established for further reduction of neonatal and infant mortality.

The Sultanate of Oman - an oil rich Arabian Gulf country - has well-organized universal free health care system assuring universal access to health care services. Following World Health Organization (WHO) guidelines, a database system has been developed and maintained throughout health care facilities. The country has made impressive gains in the achievement of key millennium development goals (MDGs) [30]. Almost all the health indicators witnessed dramatic improvements over the past four decades and it has been widely recognized and acclaimed by various international organizations, including the World Health Organization [31]. Despite all these improvements, childhood mortality and LBW remain to be a major concern for child health problem in Oman. The health service statistics of the Ministry of Health $(\mathrm{MoH})$ indicate that the infant mortality rate in Oman remains almost unchanged at a level of 10 per 1000 live birth since 2000 and LBW rates show an increasing trend since 1980s [32]. The rate of LBW is on the rise showing a steady increase reaching to $10 \%$ in 2010 as compared to $7.8 \%$ in 2000 and $4 \%$ in 1980 . As LBW is one of the most important biomarkers of health and survival of newborn babies, and hence it is important to identify underlying risk factors and establish appropriate measures to reduce the incidence of LBW in an attempt to improve the health and survival of infants.

There is scarcity of literature on levels, trends and determinants of LBW and PTB in Oman. To our knowledge, there is no comprehensive study on LBW and PTB and their determinants in Oman. The Ministry of Health of Oman provides information on LBW based on health service statistics. This lacks analysis of risk factor for LBW across the full spectrum of socioeconomic, demographic and behavioural factors. Thus, the objective of this study is to determine the incidence of PTB and LBW, and assess the associations between maternal and neonatal factors in relation to the incidence of PTB and LBW. The study eventually aims to provide information that can be used to guide to the development of preventative strategies to identify highrisk populations, in an attempt to reduce the incidence of PTB and LBW and improve infant survival.

\section{METHODS}

\section{Study Design and Participants}

This cross-sectional retrospective study was carried out at the Maternity ward, Department of Gynecology and Obstetrics, Sultan Qaboos University Hospital (SQUH), Muscat, Oman, during the period between 15 November 2011 and 18 February 2012. SQUH is a governmental educational medical institution for undergraduate and postgraduate medical training and 
research. It provides both secondary and tertiary medical care to the general population. Patients from all over Oman from any socioeconomic background have free access to health care service at SQUH. The hospital also provides free health care services to expatriate staff at Sultan Qaboos University (SQU). It is a 476-bed hospital with 396 doctors. About 3000 deliveries occur in the hospital each year.

The data for the study was extracted from the predesigned and approved data collection forms of the admissions and discharge registers of the obstetric and gynecology unit of SQUH. These standardized delivery logs contain selected vital information about maternal demographic, pregnancy and antenatal care as well as the anthropometric measurements of newborns including birth weight and gender. Nurses or midwives fill these records upon admission and immediately after delivery. All these records are routinely kept in the hospital as hard copy.

During the three-month study period, 612 delivery records were available for observation, although more than 700 deliveries were expected. The lower number of observed deliveries might be attributed to seasonal variation in delivery. This study considered delivery records with live births as eligible for enrollment in the study, excluding those who died while in hospital. All early and late fetal deaths were also excluded. Twin births were also excluded because of their well-known association with preterm births and LBW [33]. Among the observed 612 deliveries, 42 were related to fetal death, 3 were twin births, and 4 died. 29 records were discarded because of incomplete information. Ultimately, 534 records were found valid for the analysis and they constituted our target population of mothers and neonates. The sample was thought to yield valid estimates of major indicators of the study with less than $5 \%$ error margin and more than $95 \%$ confidence limit. Of the 534 deliveries, 73 were LBW, and 52 were PTB. As there were overlapped between the PTB and LBW, 38 were identified as Preterm-LBW and 35 were Term-LBW. Given that the study is a hospital-based sample, the results may not be generalizable to the national population. However, in a country like Oman where almost $100 \%$ of all expectant women attend antenatal clinics and medically assisted deliveries are almost universal, it is likely that the influence of this factor may not be substantial.

\section{Data Collection}

Ethical approval of research involving humans was obtained from Sultan Qaboos University ethics committee. This study was approved by the Department of Mathematics and Statistics and the College of Science administration. Permission to use hospital data for the study was accorded by the director general of SQUH. Data were extracted by two trained undergraduate students from Health Statistics group of the Department of Mathematics and Statistics, College of science, Sultan Qaboos University. A pre-coded case abstraction inventory was used for data extraction. The two assigned undergraduate students used to visit the Gynecology and Obstetric unit of SQUH weekly. Their duty was to collect the completed delivery log of the week and posted the relevant data into pre-coded inventory form. They worked under the supervision of the three authors and the head of midwife of SQUH. A data entry screen was designed to transfer the data from hard copy to soft copy. Data were then transferred from the Gynecology and Obstetrics unit records onto computer.

\section{Study Variables}

The main outcome variables of the study were PTB and LBW. We defined LBW as a birth weight of less than $2500 \mathrm{~g}$ irrespective of gestational age. PTB was defined as childbirth occurring before 37 completed weeks of gestation. Since there were overlapped between LBW and PTB, the study considered PretermLBW as a separate outcome variable in data analysis.

As the study was retrospective in nature and the data were extracted from the predesigned data collection forms of the admissions and discharge registers of the gynecology and obstetric unit of SQUH, a limited number of maternal and neonatal factors were available as explanatory variables. Maternal factors include demographic factors, namely age, consanguinity status, gravida, birth interval, previous story of stillbirth or miscarriage, and health factors including height, weight, and antenatal visit, and education. Neonatal factors include sex, Apgar score, mode of delivery, length of baby at birth, head circumference, delivery assistance and gestational age. Gestational age was based on the number of days between the first day of the last menstrual period (LMP) and the date of delivery expressed in completed weeks after LMP as documented in the hospital record.

Based on the frequency distributions, maternal age was categorized into four age groups, <25, 25-29, 3034 and $\geq 35$; consanguinity status was categorized into consanguineous and non-consanguineous, gravida was categorized into 1, 2-4, and 5+; birth interval was 
categorized into $<2$ years and 2 years and above; previous history of stillbirth or miscarriage was categorized as yes (one or more) and no (none). Maternal height was categorized as $<150 \mathrm{~cm}$ and $\geq 150 \mathrm{~cm}$. The maternal pre-pregnancy weight was not available. However, maternal weight at the time of booking before delivery, which we called pregnancy weight, was available in the obstetric record. Therefore, we could not calculate the standard body mass index (BMI), but maternal weight during pregnancy and maternal BMI during pregnancy can be used to evaluate their effect on LBW and PTB. Maternal education categorized into less than secondary (0-9 years of schooling), secondary (10-12 years of schooling) and higher (at least 13 years of schooling). Number of antenatal (ANC) visits were categorized into $<4$, and $\geq 4$ visits following the recommendation of World Health Organization that all women with no underlying medical problems should have a minimum of four visits [34]. However, categorizations of some of the other maternal factors were arbitrary. Among the neonatal characteristics, Apgar score during $1^{\text {st }}$ minute was categorized as $<7$ (life threatening) and $\geq 7$ (normal); length was categorized as normal $(45-55 \mathrm{~cm})$ and other than normal $(<45 \mathrm{~cm}$ and $\geq 56 \mathrm{~cm})$; head circumference was categorized as normal $(34-36 \mathrm{~cm})$ and other than normal $(<34 \mathrm{~cm}$ and $\geq 37 \mathrm{~cm})$. Categorization of all these neonatal characteristics were done following the prescribed normal range for each characteristics for an average new born baby in medical literature. Mode of delivery was categorized into spontaneous vaginal delivery (SVD) and caesarian section (CS)/assisted delivery; and delivery assistance was categorized as doctor and nurse.

\section{Statistical Analysis}

The characteristics of mothers and neonates in relation to total birth and sub-groups of births, such as LBW, PTB, and Preterm-LBW were analyzed by frequency distribution. To study the bivariate associations between outcome variables and explanatory variables, differential analysis were performed using cross tabulation and chi-square $\left(\chi^{2}\right)$ test. Factors with a p-value $<0.05$ were taken as statistically significant. While bivariate analysis identify an unadjusted effect of a predictor or explanatory variable on a outcome variable without controlling the effect of other predictors, multivariate analysis identify the adjusted effect of a predictor variable after controlling the effect of other predictors. Since our outcome variables (y say) were categorical which we dichotomized as: $y=1$ if the infants belong to any one of the sub-groups of LBW or PTB or Preterm-LBW, and $y=0$ otherwise, multivariate analysis were performed using stepwise multivariate logistic regression with backward selection so that it would identify the independent effects of predictors by eliminating the correlation effects of potential confounders. The adjusted effect of a predictor is measured by the odds ratio (OR) and the corresponding 95\% confidence interval $(\mathrm{Cl})$ with controlling the effect of all other predictors. The category of a predictor variable with theoretically low risk of LBW, or PTB or Preterm-LBW was considered as a reference category. By definition, the OR of the reference category is 1.00. An OR greater than 1.00 for a category of the predictor variable indicates higher likelihood of LBW (say) in that category as compared with that of the reference category. All analysis were done using Predictive Analytics Software (PASW) Statistics 18 version (SPSS Inc., Chicago).

\section{RESULTS}

\section{Characteristics of Sample Participants}

Table 1 shows the distribution of study sample of total births, LBW babies, PTBs, and Preterm-LBW infants according to selected characteristics of mothers and neonates. Out of total 534 sampled mothers, $22.7 \%$ were aged below 25 years, $60.5 \%$ were within the prime reproductive age $25-34$ years and $17 \%$ were aged 35 and above. Mothers' ages ranged between 18 and 47 years with a mean and SD of 28.8 and 5.32 years, respectively. About 44\% mothers had consanguineous marriage, which is lower than observed (more than $50 \%$ ) in population based national level surveys [35]. Most of the mothers (73\%) had secondary or above level education. Nearly one-fourth $(23.4 \%)$ of the mothers were primiparous. On the average mothers had more than three pregnancies indicating high-level fertility among the participating women. About 4 out of 9 mothers (46.2\%) had short birth interval of less than two years and $53.7 \%$ had birth interval two years or more. Slightly more than onefourth $(26 \%)$ mothers reported that they had previous history of stillbirth or miscarriage. Frequency of antenatal care visits indicate that $91 \%$ of mothers had at least four visits during the current pregnancy. About $10 \%$ of mothers had short stature of less than $150 \mathrm{~cm}$. More than eighty percent $(84.5 \%)$ of mothers had weight of $60 \mathrm{~kg}$ or more at the time of delivery. The distribution of maternal BMI during pregnancy shows that $80 \%$ of mothers had BMI of 25 or more. Of the 534 deliveries, half $(50.2 \%)$ were male babies and half 
Table 1: Distribution of Study Sample of Total Births, Low Birth Weight (LBW) Babies, Preterm Birth (PTB), and Preterm-LBW, According to Maternal and Neonatal Characteristics, SQUH, Oman 2012

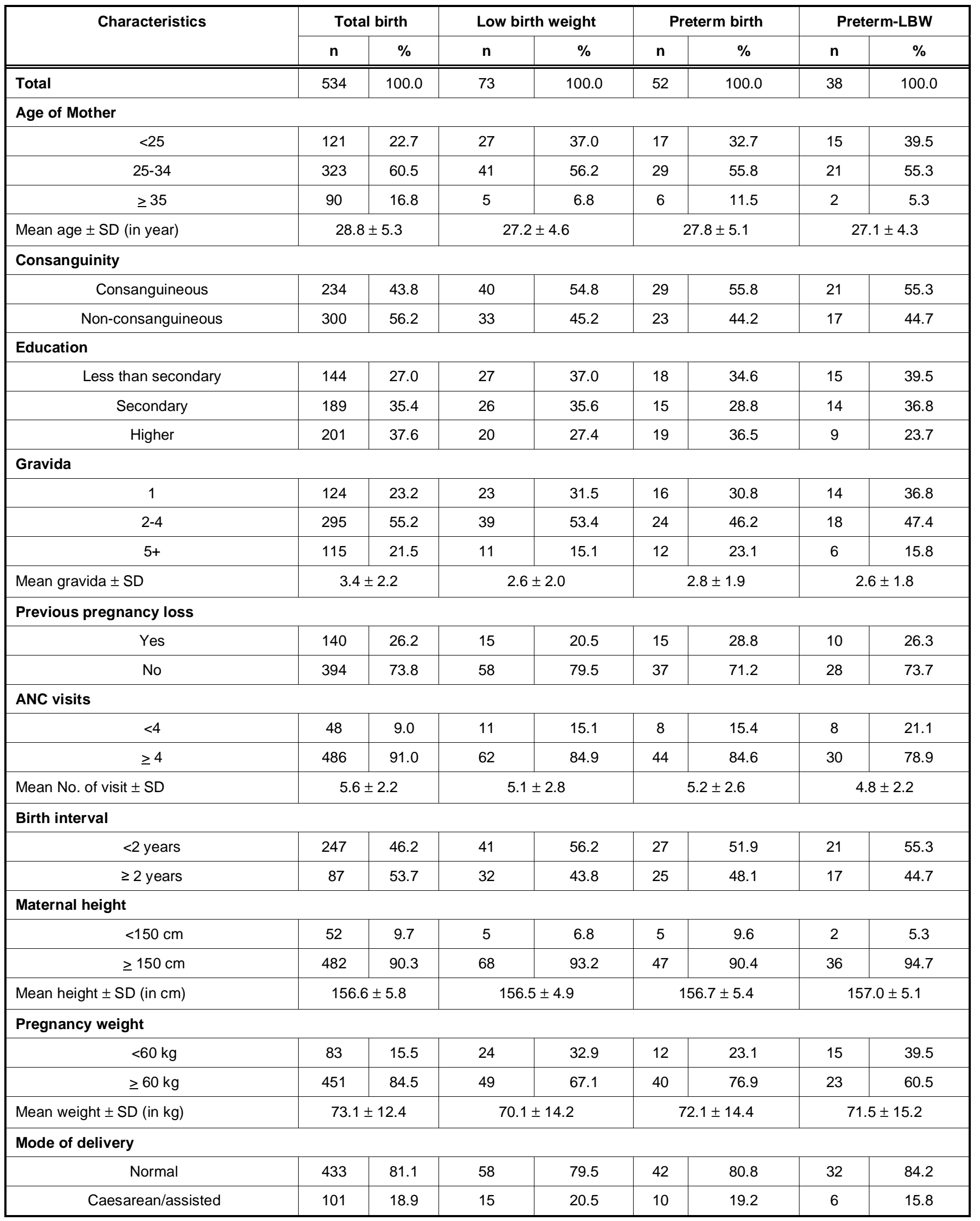


(Table 1). Continued.

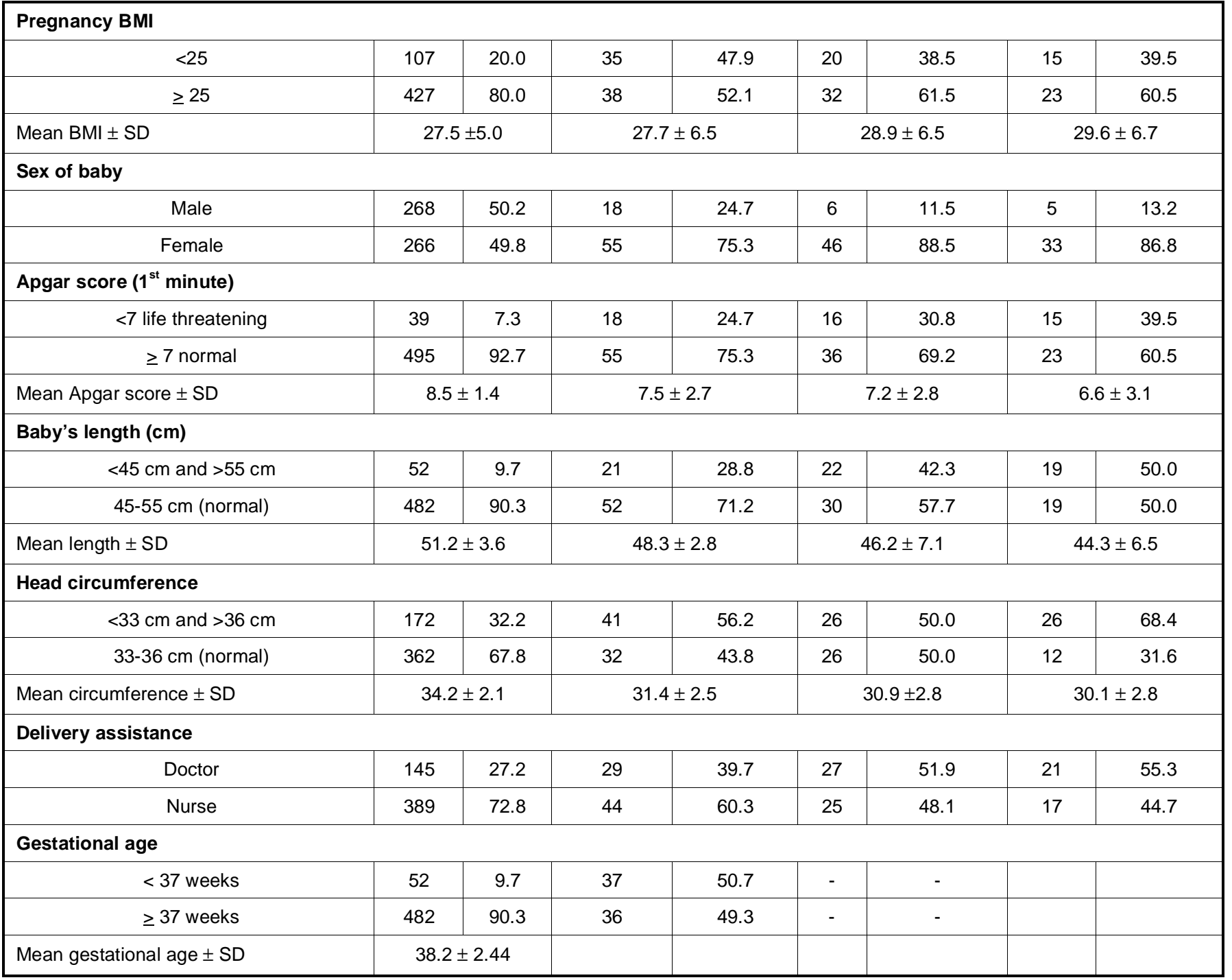

$(49.8 \%)$ were female babies. About $81 \%$ of the deliveries were spontaneous vaginal deliveries (SVD) and the rest $19 \%$ were caesarian section or assisted (by vacuum and forceps) deliveries. According to $1^{\text {st }}$ minute Apgar score, $92.7 \%$ of neonates were in normal condition (Apgar score $\geq 7$ ) and about $7 \%$ were in lifethreatening stage with Apgar score $<7$. About $90 \%$ of the babies had length within normal range of $45-55 \mathrm{~cm}$ and $86 \%$ had head circumference within normal range of $34-36 \mathrm{~cm}$. Most of the deliveries $(72.8 \%)$ were assisted by nurses.

Table 1 also presents the characteristics of subgroup of mothers with LBW, PTB, and Preterm-LBW. The results show that compare with total sample, mothers from LBW group or PTB group or PretermLBW group were relatively younger, less educated, having low average gravida, with higher value of pregnancy BMI, low average birth interval and less number of ANC visits. As expected, infants with LBW, PTB and Preterm-LBW had lower average Apgar score, length at birth and head circumference than that of total sample. The proportion of female babies were observed to be higher in all the sub-groups than that of observed in the total sample. For example, three-fourth $(75 \%)$ of the LBW babies were female compared to $50 \%$ in the total sample.

\section{Incidence of LBW, PTB and Preterm-LBW}

Table 2 presents the percentage of infants by birth weight categories, gestational age categories and gender of births. The data indicate that the incidence of LBW $(<2500 \mathrm{~g})$ was observed to be $13.7 \%$. The incidence of very low birth weight $(<1500 \mathrm{~g})$ was $2.4 \%$. The incidence of very low birth weight comprised 
Table 2: Percentage of infants by Birth Weight Category, Gestational Age Category and Gender, and Mean (SD) Birth Weight for those Categories, SQUH, Oman 2012

\begin{tabular}{|c|c|c|c|}
\hline Factors & Percentage & Number & Mean (SD) \\
\hline Birth weight (in gram) & 100.0 & 534 & $2993.9(560.0)$ \\
\hline$<1500 \mathrm{~g}$ - very low birth weight & 2.4 & 13 & $892.6(353.5)$ \\
\hline$<2500 \mathrm{~g}-$ low birth weight (LBW) & 13.7 & 73 & $2202.5(259.5)$ \\
\hline$\geq 2500 \mathrm{~g}-$ Normal weight & 86.3 & 461 & $3152.0(349.8)$ \\
\hline \multicolumn{4}{|l|}{ Gestational age } \\
\hline$<37$ weeks - preterm birth (PTB) & 9.7 & 52 & $2100.7(853.2)$ \\
\hline$\geq 37$ weeks - term birth & 90.3 & 482 & $3090.2(418.2)$ \\
\hline \multicolumn{4}{|l|}{ LBW } \\
\hline Gestational age $\geq 37$ wk (term-LBW) & 6.6 & 35 & $2262.9(335.4)$ \\
\hline $\begin{array}{c}\text { Gestational age }<37 \text { wk (preterm-LBW) } \\
\text { Normal weight }\end{array}$ & 7.1 & 38 & $1508.6(576.3)$ \\
\hline Gestational age $\geq 37 \mathrm{wk}$ & 83.5 & 446 & $3155.0(349.3)$ \\
\hline Gestational age $<37$ wk & 2.8 & 15 & $3144.0(424.8)$ \\
\hline \multicolumn{4}{|l|}{ Gender } \\
\hline Male baby & 50.2 & 268 & $3156.2(461.8)$ \\
\hline Female baby & 49.8 & 266 & $2830.4(602.1)$ \\
\hline Gestational age (in week) & 100.0 & 534 & $38.2(2.44)$ \\
\hline
\end{tabular}

$17.5 \%$ of the total LBW. The incidence of preterm births ( $<37$ weeks of gestation) was observed to be $9.7 \%$. Among the total infants, $6.6 \%$ were term-LBW babies whom we recognized as IUGR and $7.1 \%$ were pretermLBW babies. This indicates that about half $(48.2 \%)$ of the LBW babies were term births and the rest $51.8 \%$ were preterm births. Of the total infants, $83.5 \%$ were term normal-weight births and $2.8 \%$ were preterm normal-weight births. Thus $96.7 \%$ of the normal-weight babies were term births and $3.3 \%$ were preterm births. The mean birth weight was estimated to be 2993.9 $( \pm 560.0) \mathrm{g}$ and median birth weight was $3055 \mathrm{~g}$. The distribution of birth weights is shown in Figure 1, displaying an approximate normal though slightly negatively skewed (kewness $=-1.42$ ) distribution. As expected mean birth weight for male babies were higher than that of female babies (3156 g vs. $2830 \mathrm{~g}$ ) and the difference was statistically significant $(p<0.0001)$. The mean gestational age was 38 weeks ( $\mathrm{SD}=2.44$ weeks).

\section{Correlates of LBW, PTB and Preterm-LBW: Bivariate Analysis}

Table 3 presents the results of bivariate analysis showing unadjusted correlates of LBW, PTB, and Preterm-LBW. Bivaraite analysis provides percentage (or incidence) of LBW, PTB, and Preterm-LBW for each category of maternal and neonatal factors without controlling the effect of potential confounders, and thus identifies the statistically significant but unadjusted correlates of LBW, PTB and Preterm-LBW. The incidence of LBW was found to be significantly higher $(p<0.05)$ among the mothers who were young aged less than 25 years (22.3\%), having consanguineous marriage $(17.1 \%)$, had less than 4 ANC visits $(22.9 \%)$, short birth interval $(<2$ years) weight $(16.6 \%)$, with low maternal pregnancy weight $(<60 \mathrm{~kg})(33.8 \%)$ and low maternal pregnancy BMI $(<25) \quad(25.2 \%)$. All the

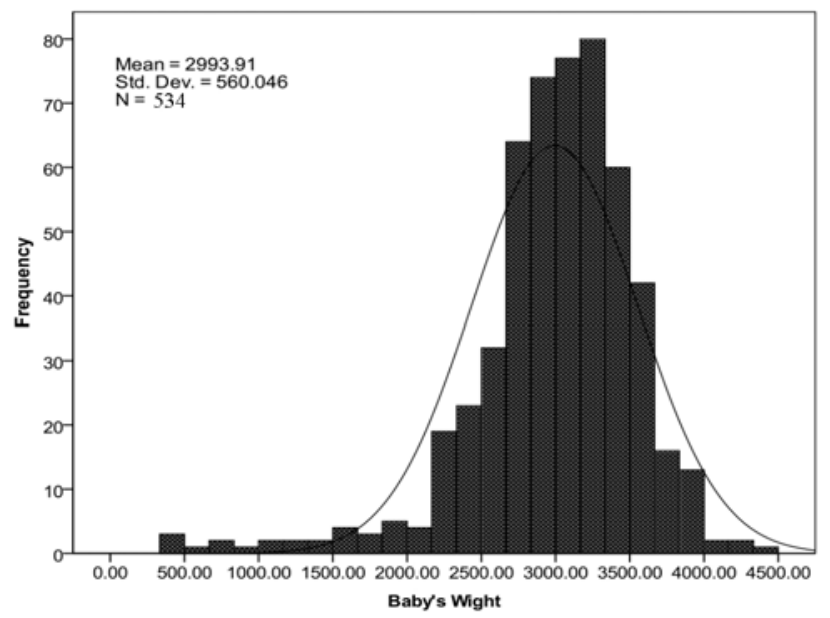

Figure 1: Histogram showing the distribution of birth weight. 
Table 3: Bivariate Analysis Showing Unadjusted Correlates of Low Birth Weight (LBW), Preterm Births (PTB), and Preterm-LBW, According to Maternal and Neonatal Characteristics, SQUH, Oman 2012

\begin{tabular}{|c|c|c|c|c|c|c|c|c|c|}
\hline \multirow[t]{2}{*}{ Characteristics } & \multicolumn{3}{|c|}{ Low birth weight } & \multicolumn{3}{|c|}{ Preterm birth } & \multicolumn{3}{|c|}{ Preterm-LBW } \\
\hline & $\mathbf{n}$ & $(\%)$ & p-value & $\mathbf{n}$ & $\%)$ & P-value & $\mathbf{n}$ & $\%$ & $p$-value \\
\hline Total & 73 & 13.7 & & 52 & 9.7 & & 38 & 7.1 & \\
\hline Age of Mother & & & 0.003 & & & 0.016 & & & 0.023 \\
\hline$<25$ & 27 & 22.3 & & 17 & 14.0 & & 15 & 12.4 & \\
\hline $25-34$ & 41 & 12.7 & & 29 & 9.0 & & 21 & 6.5 & \\
\hline Consanguinity & & & 0.045 & & & 0.070 & & & 0.142 \\
\hline Consanguineous & 40 & 17.1 & & 29 & 12.4 & & 21 & 9.0 & \\
\hline Non-consanguineous & 33 & 11.0 & & 23 & 7.7 & & 17 & 5.7 & \\
\hline Education & & & 0.092 & & & 0.379 & & & 0.159 \\
\hline Higher & 20 & 10.0 & & 19 & 9.5 & & 9 & 4.5 & \\
\hline Gravida & & & 0.047 & & & 0.316 & & & 0.162 \\
\hline 1 & 23 & 18.5 & & 16 & 12.9 & & 14 & 11.3 & \\
\hline $2-4$ & 39 & 13.2 & & 24 & 8.10 & & 18 & 6.1 & \\
\hline $5+$ & 11 & 9.6 & & 12 & 10.4 & & 6 & 5.2 & \\
\hline Previous pregnancy loss & & & 0.238 & & & 0.031 & & & 0.863 \\
\hline Yes & 15 & 10.7 & & 15 & 10.7 & & 10 & 7.1 & \\
\hline No & 58 & 14.7 & & 37 & 9.4 & & 28 & 7.1 & \\
\hline Maternal height & & & 0.374 & & & 0.975 & & & 0.381 \\
\hline$<150 \mathrm{~cm}$ & 5 & 9.6 & & 5 & 9.6 & & 2 & 3.8 & \\
\hline$\geq 150 \mathrm{~cm}$ & 68 & 14.1 & & 47 & 9.8 & & 36 & 7.5 & \\
\hline Maternal pregnancy weight & & & $<0.001$ & & & 0.150 & & & 0.073 \\
\hline$<60 \mathrm{~kg}$ & 24 & 33.8 & & 12 & 14.5 & & 15 & 18.1 & \\
\hline$\geq 60 \mathrm{~kg}$ & 49 & 10.6 & & 40 & 8.9 & & 23 & 5.1 & \\
\hline Mode of delivery & & & 0.704 & & & 0.951 & & & 0.721 \\
\hline Normal & 58 & 13.4 & & 42 & 9.7 & & 32 & 7.4 & \\
\hline Caesarean/assisted & 15 & 14.9 & & 10 & 10.0 & & 6 & 5.9 & \\
\hline Pregnancy BMI & & & $<0.001$ & & & 0.048 & & & 0.103 \\
\hline$<25$ & 27 & 25.2 & & 13 & 12.1 & & 15 & 14.0 & \\
\hline$\geq 25$ & 44 & 10.3 & & 39 & 9.1 & & 23 & 5.4 & \\
\hline Sex of baby & & & $<0.001$ & & & $<0.001$ & & & $<0.001$ \\
\hline Male & 18 & 6.7 & & 6 & 2.2 & & 5 & 1.9 & \\
\hline
\end{tabular}




\begin{tabular}{|c|c|c|c|c|c|c|c|c|c|}
\hline Apgar score ( $1^{\text {st }}$ minute) & & & $<0.001$ & & & $<0.001$ & & & $<0.001$ \\
\hline$\geq 7$ normal & 55 & 11.1 & & 36 & 7.3 & & 23 & 4.4 & \\
\hline Baby's length (cm) & & & $<0.001$ & & & $<0.001$ & & & $<0.001$ \\
\hline $45-55 \mathrm{~cm}$ (normal) & 52 & 10.8 & & 30 & 6.2 & & 19 & 3.9 & \\
\hline Head circumference & & & $<0.001$ & & & $<0.001$ & & & $<0.001$ \\
\hline$<34 \mathrm{~cm}$ and $>36 \mathrm{~cm}$ & 41 & 54.7 & & 26 & 34.7 & & 26 & 15.1 & \\
\hline $34-36 \mathrm{~cm}$ (normal) & 32 & 7.0 & & 26 & 5.7 & & 12 & 3.3 & \\
\hline Gestational age & & & $<0.001$ & & & & & & \\
\hline$<37$ weeks & 37 & 71.2 & & - & - & & - & - & \\
\hline$\geq 37$ weeks & 36 & 7.5 & & - & - & & - & - & \\
\hline
\end{tabular}

neonatal factors such as sex, Apgar score, length at birth, head circumference, gestational age and delivery assistance showed significant association with LBW (Table 3). Maternal level of education show no significant differential effect on LBW ( $p=0.092)$.

The incidence of PTB was found to be significantly $(\mathrm{p}=0.045)$ higher among the mothers who were aged $<25$ years, had previous pregnancy loss history, had low ANC visit frequency ( $<4$ visits), had low pregnancy weight and low pregnancy BMI. All the neonatal factors showed significant association with PTB. Preterm-LBW was found to have significant association with maternal age and ANC visits. Like LBW and PTB, Preterm-LBW also showed significant association with all the neonatal factors. The incidence of LBW was found to be highest $(71.2 \%)$ for short gestational age, closely followed by other than normal head circumference $(54.7 \%)$, low apgar score (46.2\%) and other than normal length of baby (40.4\%). On the other hand, the highest level of incidence of PTB was found for other than normal length of baby (42.3\%), followed by low Apgar score (41\%) and other than normal head circumference of baby (34.7\%).

\section{Determinants of LBW, PTB and Preterm-LBW: Multivariate Analysis}

Table 4 presents multivariate logistic regression analysis showing adjusted odds of maternal and neonatal factors on LBW, PTB, and Preterm-LBW.
After controlling for the confounding effects of the maternal and neonatal risk factors of LBW in multivariate logistic regression model, gestational age less than 37 weeks appeared as the most strongest predictor of LBW (AOR=20.16; 95\% Cl: 8.32, 55.18), followed by other than normal head circumference of newborn (AOR=14.57; 95\% Cl:7.05, 31.15). Other independent risk factors of LBW, as indicated by the adjusted model, included low Apgar score $(<7)$ (AOR=5.67; 95\% Cl:2.64, 12.34), female baby (AOR=4.13; 95\% Cl:2.18, 8.39), low maternal pregnancy weight $(<60 \mathrm{~kg})(\mathrm{AOR}=3.04 ; 95 \% \mathrm{Cl}: 1.50$, 6.21 ), short birth interval ( $<2$ years) ( $A O R=1.58 ; 95 \%$ $\mathrm{Cl}$ : 0.47, 2.79), low maternal pregnancy BMI $(<25)$ $(\mathrm{AOR}=2.01 ; 95 \% \mathrm{Cl}: 0.70,3.24)$ and less than 4 ANC visits $(A O R=1.98 ; 95 \% \mathrm{Cl}: 0.67,4.28)$. Although the unadjusted bivariate analysis identified maternal age, consanguinity, gravida and length of baby at birth as significant correlates of LBW, the effect of these factors become statistically insignificant after controlling the effects of other factors.

The results from multivariate logistic regression analysis of PTB (Table 4) revealed that PTB has significant association with low maternal age of less than 25 years (AOR=5.86; 95\% Cl:1.22, 28.28), maternal previous pregnancy loss experience $(A O R=1.51 ; 95 \% \mathrm{Cl}: 0.39,3.19)$, less than $4 \mathrm{ANC}$ visits (AOR $=1.28 ; 95 \% \quad \mathrm{Cl}: 0.37,3.82$ ), female baby (AOR=8.58; 95\% Cl:3.81, 19.32), low Apgar score $(\mathrm{AOR}=7.41 ; 95 \% \mathrm{Cl}: 3.50,16.28)$, length of baby 
Table 4: Logistic Regression Analysis of LBW Showing Unadjusted and Adjusted Odds Ratio (OR) with $95 \% \mathrm{Cl}$, According to Maternal and Neonatal Risk Factors, SQUH, Oman 2012

\begin{tabular}{|c|c|c|c|c|c|c|}
\hline \multirow[b]{2}{*}{ Risk factors } & \multicolumn{2}{|c|}{ Low birth weight } & \multicolumn{2}{|c|}{ Preterm birth } & \multicolumn{2}{|c|}{ Preterm-LBW } \\
\hline & $\begin{array}{c}\text { Adjusted } \\
\text { OR }\end{array}$ & $(95 \% \mathrm{Cl})$ & $\begin{array}{l}\text { Adjusted } \\
\text { OR }\end{array}$ & $(95 \% \mathrm{Cl})$ & $\begin{array}{l}\text { Adjusted } \\
\text { OR }\end{array}$ & $(95 \% \mathrm{Cl})$ \\
\hline \multicolumn{7}{|l|}{ Age of Mother } \\
\hline$<25$ & & & 5.86 & $(1.22,28.28)^{*}$ & 9.58 & $(1.51,30.22)^{*}$ \\
\hline $25-34$ & & & 2.59 & $(0.70,10.84)$ & 4.57 & $(0.62,18.34)$ \\
\hline$\geq 35$ & & & 1.00 & Reference & 1.00 & Reference \\
\hline \multicolumn{7}{|l|}{ Previous pregnancy loss } \\
\hline Yes & & & 1.51 & $(0.39,3.19)^{*}$ & & \\
\hline No & & & 1.00 & Reference & & \\
\hline \multicolumn{7}{|l|}{ ANC visits } \\
\hline$<4$ & 1.98 & $(0.67,4.28)^{\star}$ & 1.28 & $(0.37,3.82)^{*}$ & & \\
\hline$\geq 4$ & 1.00 & Reference & 1.00 & Reference & & \\
\hline \multicolumn{7}{|l|}{ Birth interval } \\
\hline$<2$ years & 1.58 & $(0.47,2.79)^{*}$ & & & & \\
\hline$\geq 2$ years & 1.00 & Reference & & & & \\
\hline \multicolumn{7}{|l|}{ Maternal height } \\
\hline \multicolumn{7}{|l|}{$<150 \mathrm{~cm}$} \\
\hline \multicolumn{7}{|l|}{$\geq 150 \mathrm{~cm}$} \\
\hline \multicolumn{7}{|l|}{ Maternal pregnancy weight } \\
\hline$<60 \mathrm{~kg}$ & 3.04 & $(1.50,6.21)^{\star *}$ & & & & \\
\hline$\geq 60 \mathrm{~kg}$ & 1.00 & Reference & & & & \\
\hline \multicolumn{7}{|l|}{ Pregnancy BMI } \\
\hline$<25$ & 2.01 & $(0.70,3.24)^{*}$ & & & & \\
\hline$\geq 25$ & 1.00 & Reference & & & & \\
\hline \multicolumn{7}{|l|}{ Sex of baby } \\
\hline Male & 1.00 & Reference & 1.00 & Reference & 1.00 & Reference \\
\hline Female & 4.13 & $(2.18,8.39)^{\star * *}$ & 8.58 & $(3.81,19.32)^{\star \star *}$ & 8.01 & $(2.37,26.11)^{* *}$ \\
\hline \multicolumn{7}{|l|}{ Apgar score at $1^{\text {st }}$ minutes } \\
\hline$<7$ life threatening & 5.67 & $(2.64,12.34)^{\star * *}$ & 7.41 & $(3.50,16.28)^{\star \star *}$ & 8.47 & $(5.84,42.23)^{\star * *}$ \\
\hline$\geq 7$ normal & 1.00 & Reference & 1.00 & Reference & 1.00 & Reference \\
\hline \multicolumn{7}{|l|}{ Baby's length $(\mathrm{cm})$} \\
\hline$<45 \mathrm{~cm}$ and $>55 \mathrm{~cm}$ & & & 5.97 & $(2.26,17.40)^{* * *}$ & 5.38 & $(1.82,15.30)^{* *}$ \\
\hline $45-55 \mathrm{~cm}$ (normal) & & & 1.00 & Reference & 1.00 & Reference \\
\hline \multicolumn{7}{|l|}{ Head circumference } \\
\hline$<34 \mathrm{~cm}$ and $>36 \mathrm{~cm}$ & 14.57 & $(7.05,31.15)^{\star * \star}$ & 3.57 & $(1.49,8.52)^{\star *}$ & & \\
\hline $34-36 \mathrm{~cm}$ (normal) & 1.00 & Reference & 1.00 & Reference & & \\
\hline \multicolumn{7}{|l|}{ Gestational age } \\
\hline$<37$ weeks & 20.16 & $(8.32,55.18)^{\star \star *}$ & & & & \\
\hline$\geq 37$ weeks & 1.00 & Reference & & & & \\
\hline
\end{tabular}

${ }^{*} p<0.05,{ }^{* *} p<0.01,{ }^{* * *} p<0.001$. 
(AOR=5.97; 95\% Cl: 2.26, 17.40) and head circumference of baby $(\mathrm{AOR}=3.57 ; 95 \% \mathrm{Cl}$ : 1.49 , 8.52).

For both preterm and LBW infants, maternal age less than 25 years (AOR=9.58; 95\% Cl: 1.51, 30.22), maternal previous pregnancy loss experience (AOR=4.57; 95\% Cl: $0.62,18.34)$, female baby (AOR=8.01; (5\% Cl: 2.37, 26.11), low Apgar score (AOR=8.47; 95\%Cl: $5.84,42.23$ ) and other than normal length of baby (AOR=5.38; 95\% Cl:1.82, 15.30) appeared as significant predictors.

\section{DISCUSSION}

The purpose of this study was to determine the incidence of LBW, PTB and Preterm-LBW and identify the maternal and neonatal risk factors influencing them, using data from a cross-sectional retrospective study conducted at the maternity ward of Sultan Qaboos University Hospital (SQUH) in Oman. Our estimates of incidence of LBW (13.7\%) and PTB (9.7\%) appeared to be high compared to other developed and many Arab countries $[5,11]$. The reported percentage of LBW in this study is slightly higher than reported by the annual health report of Ministry of Health (MoH) of Oman [32]. Based on health service statistics, $\mathrm{MoH}$ reported an estimate of $10 \%$ LBW in Oman in 2010. There is dearth of published comparable population based data on LBW and PTB in Oman. As the hospital provides neonatal intensive care services and women with high risk pregnancies would be more likely to choose this specific hospital for the delivery, a factor that may lead to overestimating the observed LBW and PTB rates in this study. On the other hand, the estimates of LBW and PTB may be underestimated due to some eligibility criteria for selecting the sample of this study that excluded all twin births and births with missing information. Nevertheless, the estimates are plausible, as they lie within observed range for developing countries as reported by the joint study of UNICEF and WHO [5].

The study provides a comparative analysis of the risk factors for LBW, PTB and Preterm-LBW which is useful because these indicators would likely to have different etiologies. In addition, PTB is the major predictor of LBW babies but the converse may not be true.

Multivariate logistic regression analysis showed that ANC visit, infant's gender, Apgar score, and head circumference of infants were the common significant risk factors influencing both LBW and PTB. Thus, the risk profile for the two outcomes groups had both differences and similarities. This study found that the risk factors specific to PTB were maternal age, previous history of pregnancy loss, and infant's length, while birth interval, maternal pregnancy weight, pregnancy $\mathrm{BMI}$ and gestational age were the risk factors unique to LBW in addition to aforementioned observed common factors for both LBW and PTB.

Low gestation age appeared as the factor that had the highest association with LBW. Infants with gestation age less than 37 weeks i.e. PTBs were 20 times more likely to be LBW compared with infants born at 37 weeks or thereafter $(A O R=20.13 ; 95 \% \mathrm{Cl}$ : $8.21,55.22)$. The results are in line with findings reported by many previous studies [5, 36-38].

The association between maternal pre-pregnancy nutrition and LBW and PTB could not be examined in this study due to lack of pre-pregnancy weight of mothers. However, data on maternal weight at booking before delivery were available, and therefore we used maternal pregnancy weight and the corresponding pregnancy $\mathrm{BMI}$ to examine the association between maternal nutrition and LBW or PTB. LBW was found significantly associated with low maternal pregnancy weight as well as low pregnancy BMI as a result of low body weight in relation to height. This could be attributed to limited maternal weight gain during pregnancy and other factors that can be associated with maternal nutrition including infections, lifestyle, food habit and socio-economic status of mothers. The association between maternal pregnancy weight and LBW observed in this study is consistent with findings of the large meta-analysis of data from all over the world conducted by the World Health Organization (WHO) [39]. Similar findings were reported by others in different settings [28, 29, 40, 41]. Maternal pregnancy weight and pregnancy $\mathrm{BMI}$, and thus nutrition level, however did not show significant association with PTB, although low pregnancy weight $(<60 \mathrm{~kg})$ and BMI showed increased risk of PTB. Maternal height did not show any significant association with LBW and PTB.

Birth spacing showed independent effect on LBW in our study population. Both unadjusted and adjusted analysis identified birth interval as a significant predictor of LBW. Mothers with short birth intervals of less than two years were at least 1.5 times more likely to produce LBW baby compared with mothers having birth interval two years or more. Similar findings were documented by many previous studies [28, 29, 42-45]. Birth interval did not show significant association with 
PTB. Due to prevailing high fertility [46] and demand for large family size, birth interval is relatively short in Oman (about 2.5 years) [47]. Among the mothers considered in this study, $46 \%$ had birth interval less than 2 years. In this context, the finding that short birth intervals are associated with adverse pregnancy outcomes has important policy implications for Oman. The incidence of LBW could effectively be reduced by implementing strategies aimed at increasing birth spacing in Oman. It is encouraging to note that Ministry of Health has already initiated birth spacing program in 1994 as an integral part of 'Maternal and Child Health Care' development in Oman. Government's effort appear to be on the right track.

Like most Arab communities, consanguineous marriage is a deeply rooted cultural trend in Oman and more than half $(52 \%)$ of the marriages are consanguineous marriage [35]. The long tradition of high prevalence of consanguineous marriage in Omani society was found to have association with reproductive behavior and health and survival of newborns [48]. This study examined possible association between high rate of consanguineous marriages in Oman and LBW and PTB. Although, our unadjusted bivariate analysis showed some marginal effect of consanguinity on LBW and PTB in Oman, but after controlling other factors in multivariable analysis, its effect on LBW and PTB become insignificant. Similar association between first cousin marriage and LBW was observed by Dawodu et al. [29] in the United Arab Emirates. In a meta-analysis, Kramer [3] concluded that genetic factors may play an important role in LBW. Considering the high incidence of consanguineous marriage in Oman, it could be an important genetic factor for LBW and PTB and warrants the need for more research.

Our analysis revealed that the frequency of antenatal care (ANC) visits had significant independent effects on both LBW and PTB. The effectiveness of timely adequate number of ANC is well established in reducing the risk of adverse pregnancy outcomes [4951]. As almost all women (99.4\%) in Oman received ANC at least once during pregnancy [32], this could be an important avenue for screening medical and obstetric complications so that timely interventions and treatment can be given to reduce the risk of LBW and PTB.

Young mothers aged less than 25 and mothers with prior history of stillbirth or miscarriage (pregnancy loss) were found to be at higher risk of PTB. The risk of PTB was observed to be 1.5 times higher among women with a history of prior pregnancy loss as compared to those without a history of pregnancy loss.

The findings of this study indicate that female sex, low Apgar score of birth (less than 7), head circumference and body length of baby less than or greater than normal range were associated with higher risk of both LBW, PTB and Preterm-LBW. All these neonatal factors have direct and indirect link with maternal nutrition and several non-nutritional factors such as infections, hypertension, smoking, environmental factors, socio-economic status and genetics $[52,53]$.

The finding that female babies are at higher risk of LBW and PTB warrant special attention because of its potential intergenerational effects. Many studies documented a classic pattern of intergenerational growth failure of female infants, mostly in developing countries, that girls born with LBW continue to experience growth failure during their early childhood and adulthood, and they most likely have children at an early age (which further reduces their opportunity to reach an optimal body size with adequate nutrient stores before conception), and thereby give birth to LBW infants [53-56]. As intergenerational effect is linked with many factors such as genetics, culture and belief, environment and women status [42], reduction of its influence on birth outcomes across generation will also take a long time. However, improving dietary intakes during pregnancy through micronutrient supplementation could be an important solution for reducing LBW. Several efficacy trials have shown that food supplementation or improving food intake during pregnancy effectively reduces LBW [53]. Based on a meta-analysis of controlled trials, Kramer [23] concluded that balanced protein-energy supplements during pregnancy can reduce the incidence of smallfor-gestational-age infants by almost one-third.

Some limitations of this study are worth mentioning. It is difficult to generalize our findings due to selection bias as the study focused on births that occurred within SQUH maternity unit. Given the retrospective nature of the study, and due to lack of relevant data in the medical records, we were unable to examine many important risk factors such as socioeconomic status of mothers, their diet and life style, their physical and mental health, their chronic and comorbid conditions, and other obstetric complications. In addition, data on infant's physical conditions, such as congenital disease and complications etc. were not available. It was not 
unlikely that factors not included in this study would have contributed to some of the unexplained variation for PTB and LBW in this population [6]. Gestational age records derived from maternal accounts of LMP may sometimes be prone to errors, and thus some error in the classification of preterm births is likely. Nevertheless, the study was an exploratory study to provide updated information for maternity service providers, particularly the obstetric care providers to enhance their preconceptual and antenatal counseling. The study findings have also clinical significance as the findings of the study suggest that most of the factors associated with adverse birth outcomes are modifiable with appropriate maternal and child health services. Health information, education, and counseling, improvement of maternal nutrition, and increasing the use of ANC services during pregnancy, are all important for reducing LBW and PTB.

The findings of the study highlight the need of intervention for specific groups of women with higher risk of LBW and PTB. Young women aged less than 25 , and those with previous history of pregnancy loss, short inter-pregnancy interval, low weight and BMI during pregnancy, low frequency of ANC visits and with consanguineous marriage should be informed of their relatively higher risks of LBW and PTB and be given proper attention during antenatal care. The persistent high prevalence of consanguineous marriage in Oman and its link with LBW and PTB need to be considered in its public health strategy. Culturally appropriate genetic counseling and genetic educational programs related to consanguineous marriage should be undertaken in order to reduce the incidence of consanguineous marriages and its impact on reduction of birth weight.

\section{ACKNOWLEDGEMENTS}

The authors wish to acknowledge Mr. Yaqoob Nasser Al-Amri and Mr. Mahmood Rashid Al-Masroori, Health Statistics group, Department of Statistics and Mathematics, SQU, for their sincere effort in collecting and preparing data file. Thanks go to the administration and staff of the Medical Record Unit of the SQUH for permission to access the data. Special thank goes to Ms Barbara Swales, head midwife, delivery ward, SQUH, for her nice cooperation and help in collecting data. This research work does not involve any fund from any organization.

\section{CONFLICT OF INTEREST}

There are no conflicts of interest for any of the authors.

\section{AUTHORS' CONTRIBUTIONS}

MMI designed the study, monitored the data collection, analyzed the data, and wrote the first draft of the manuscript. KA and MA participated in the design of the study, supervised the whole process and reviewed and modified the drafts of the manuscript. All authors revised and approved the final version of this manuscript.

\section{ABBREVIATIONS}

$\mathrm{OR}=$ Odds ratio
$\mathrm{AOR}=$ adjusted odds ratio
$\mathrm{CI}=$ confidence intervals
$\mathrm{LBW}=$ low birth weight
$\mathrm{PTB}=$ preterm birth
$\mathrm{SD}=$ standard deviation
$\mathrm{IUGR}=$ intrauterine growth retardation
$\mathrm{BMI}=$ body mass index
$\mathrm{LMP}=$ last menstrual period WHO- World Health

\section{REFERENCES}

[1] World Health Organization, International statistical classification of diseases and related health problems, tenth revision, World Health Organization, Geneva 1992.

[2] McCormick M. The contribution of low birth weight to infant mortality and childhood morbidity. New Engl J Med 1985; 312: 82-90.

http://dx.doi.org/10.1056/NEJM198501103120204

[3] Kramer MS. Determinants of low birth weight: methodological assessment and meta-analysis. Bull World Health Organization 1987; 65: 663-37.

[4] Wilcox AJ. On the importance - and the unimportance - of birth weight. Int J Epidemiol 2001; 30: 1233-41. http://dx.doi.org/10.1093/ije/30.6.1233

[5] UNICEF, WHO. Low Birth weight: Country, Regional and Global Estimates. United Nations Children's Fund (UNICEF), New York, and WHO, Geneva 2004.

[6] Goldenberg RL, Culhane JF, lams JD, Romero R. Epidemiology and causes of preterm birth. Lancet 2008; 371: 75-84.

http://dx.doi.org/10.1016/S0140-6736(08)60074-4

[7] Lawn JE, Cousens S, Zupan J, Lancet Neonatal Survival Steering T. 4 million neonatal deaths: when? Where? Why? Lancet 2005; 365: 891-900.

[8] Strauss RS. Adult functional outcome of those born small for gestational age: wenty-six-year follow-up of the 1970 British birth cohort. J Am Med Assoc 2000; 283: 625-32. http://dx.doi.org/10.1001/jama.283.5.625

[9] Barker DJP. In utero programming of chronic disease. Clinical Science 1998; 95: 115-28.

http://dx.doi.org/10.1042/CS19980019 
[10] Huxley RR. Shiell AW, Law CM. The role of size at birth and postnatal catch-up growth in determining systolic blood pressure: a systematic review of the literature. $\mathrm{J}$ Hypertension 2000; 18: 815-31.

http://dx.doi.org/10.1097/00004872-200018070-00002

[11] Blencowe H, Cousens S, Oestergaard MZ, Chou D, Moller A, Narwal R, et al. National, regional, and worldwide estimates of preterm birth rates in the year 2010 with time trends since 1990 for selected countries: a systematic analysis and implications. Lancet 2012; 379: 2162-72.

[12] Liu L, Johnson HL, Cousens S, Perin J, Scott S, Lawn JE, et al. Global, regional, and national causes of child mortality: an updated systematic analysis for 2010 with time trends since $2000 . \quad$ Lancet 2012; 379: 2151-61. http://dx.doi.org/10.1016/S0140-6736(12)60560-1

[13] United Nations Children's Fund (UNICEF). The state of the world's children 2009. New York, USA 2008.

[14] United Nations (UN). Resolution adopted by the General Assembly, Twenty-seventh special session, S-27/2. A world fit for children, New York, USA 2002.

[15] Bhargava SK, Ramji S, Kumar A. Mid-arm and chest circumferences at birth as predictors of low birth weight and neonatal mortality in the community. Br Med J 1985; 291: 1617-19.

http://dx.doi.org/10.1136/bmj.291.6509.1617

[16] Mohsin M, Bauman A. Maternal health and births in SWSAHS and NSW. Epidemiological Bulletin (Epidemiology Unit, SWSAHS) 1997; 3: 1-6.

[17] Kramer MS, Séguin L, Lydon J, Goulet L. Socio-economic disparities in pregnancy outcome: why do the poor fare so poorly? Paediatr Perinatal Epidemiol 2000; 14: 194-10.

[18] Tsimbos C, Verropoulou G. Demographic and socioeconomic determinants of low birth weight and preterm births among natives and immigrants in Greece: An analysis using nationwide vital registration micro-data. J Biosoc Sci 2011; 43: $271-83$

http://dx.doi.org/10.1017/S0021932010000726

[19] Frisbie WP, Forbes D, Pullum SG. Compromised birth outcomes and infant mortality among racial and ethnic groups. Demography 1996; 33: 469-81. http://dx.doi.org/10.2307/2061781

[20] Astolfi P, Zonta LA. Risks of preterm delivery and association with maternal age, birth order and fetal gender. Human Reproduction 1999; 14(11): 2891-94.

http://dx.doi.org/10.1093/humrep/14.11.2891

[21] Meggiolaro S. Low birth weight and parental resources in Italy. Genus 2009; 65(1): 103-21.

[22] Bener A, Abdulrazzaq YM, Dawodu A. Sociodemographic risk factors associated with low birth weight in United Arab Emirates. J Biosoc Sci 1996; 28: 339-46. http://dx.doi.org/10.1017/S0021932000022409

[23] Kramer MS. The epidemiology of adverse pregnancy outcomes: an overview. J Nutr 2003; 133: 1592-96.

[24] Machado CJ. Impact of maternal age on birth outcomes: a population-based study of primiparous Brazilian women in the city of Sao Paulo. J Biosoc Sci 2006; 38: 523-35. http://dx.doi.org/10.1017/S0021932005026660

[25] Letamo G, Majelantle RG. Factors influencing low birth weight and prematurity in Botswana. J Biosoc Sci 2001; 33: 391-403.

http://dx.doi.org/10.1017/S0021932001003911

[26] Rodriguez C, Regidor E, Gutierrez-Fisac JL. Low birth weight in Spain associated with sociodemographic factors. J Epidemiol Commun Health 1995; 49: 38-42. http://dx.doi.org/10.1136/jech.49.1.38

[27] Ksmodel U, Wisborg K, Olsen SF, Henriksen TB, Secher NJ. Moderate alcohol intake during pregnancy and the risk of stillbirth and death in the first year of life. Am $\mathrm{J}$ Epidemiol 2002; 155: 305-12.

http://dx.doi.org/10.1093/aje/155.4.305

[28] Mavalankar DV, Gray RH, Trivedi CR. Risk factors for preterm and term low birth weight in Ahmedabad, India. Int $\mathrm{J}$ Epidemiol 1992; 21: 263-72.

http://dx.doi.org/10.1093/ije/21.2.263

[29] Dawodu A, Abdulrmzaq YM, Bener A, Kappel I, Liddle L, Vargheses M. Biologic Risk Factors for Low Birth weight in A Ain, United Arab Emirates. Am J Human Biol 1996; 8: 34145.

[30] Al-Lamki L. UN Millennium Development Goals and Oman Sultan Qaboos University Med J 2010; 10: 301-305.

[31] World Health Organization. Health systems: improving performance-The world health report 2000. http:// www.who.int/whr/2000/en, Geneva: WHO, 2000.

[32] Ministry of Health (MoH). Annual Health Report 2010. Muscat: Ministry of Health, Muscat: Sultanate of Oman, 2012.

[33] Blondel B, Kogan MD, Alexander GR, et al. The impact of the increasing number of multiple births on the rates of preterm birth and low birth weight: An international study. Am J Publ Health 2002; 92: 1323-30.

http://dx.doi.org/10.2105/AJPH.92.8.1323

[34] Carroli G, Villar J, Piaggio G, Khan-Neelofur D, Gülmezoglu $\mathrm{M}$, Mugford $\mathrm{M}$, et al. WHO systematic review of randomised controlled trials of routine antenatal care. Lancet 2001; 357: 1565-70.

http://dx.doi.org/10.1016/S0140-6736(00)04723-1

[35] Islam MM. The practice of consanguineous marriage in Oman: prevalence, trends and determinants. J Biosoc Sci 2012; 44: 571-94.

http://dx.doi.org/10.1017/S0021932012000016

[36] Villar J, Belizan JM. The relative contribution of prematurity and fetal growth retardation to low birth weight in developing countries and developed societies. Am J Obstetr Gynecol 1982; 143: 793-98.

[37] Kramer MS, McLean FH, Eason EL, Usher RH. Maternal nutrition and spontaneous pre-term birth. Am $\mathrm{J}$ Epidemiol 1992; 136: 574-83.

[38] Jurjus AR. Low birth weight in Lebanon: morphological parameter and a health status indicator. Eastern Mediterranean Health J 1995; 1: 194-200.

[39] World Health Organization (WHO). Maternal anthropometry and pregnancy outcomes: a WHO collaborative Study. Bulletin of World Health organization 1995; 73(Suppl): 1-98.

[40] Neyzi O, Gunoz H, Celenk A, Dindar A, Bundak R. Birth weight in Turkish infants. Human Biol 1986; 58: 367-78.

[41] Finnemore BI. Low birth weight in the Central Canadian Arctic. Arctic Med Res 1992; 51: 117-25.

[42] Brody DJ, Bracken MB. Short interpregnancy interval: A risk factor for low birth weight. Am J Perinatol 1987; 4: 50-54. http://dx.doi.org/10.1055/s-2007-999736

[43] Vijayakumar K. Birth Spacing and its Bearing on Birth weight. Indian J Commun Med 1992; 17: 15-20.

[44] Das JC, Khanam ST. Correlation of anthropometric measurements of mothers and their newborns. Bangl Med Res Council Bull 1997; 23: 10-15.

[45] Deswal BS, Singh JV, Kumar D. A study of risk factors for low birth weight. Indian J Commun Med 1999; 24: 127-31.

[46] Islam MM, Atsu SSD, Al-Qasmi AM. Proximate determinants of declining fertility in Oman. Can Stud Populat 2011; 38: 151-70.

[47] Al-Riyami A, Afifi M, Al-Kharusi H, Morsi M. National Health Survey, 2000, Volume 2, Reproductive Health Survey, Muscat: Ministry of Health, Sultanate of Oman 2000. 
[48] Islam MM. Effects of consanguineous marriage on reproductive behavior, adverse pregnancy outcomes and offspring mortality in Oman. Annals Human Biol 2013; 40: 243-55.

http://dx.doi.org/10.3109/03014460.2012.760649

[49] Hollander D. Prenatal benefits improve birth outcomes among working Mexican women. International Family Planning Perspectives 1997; 23: 94-105. http://dx.doi.org/10.2307/2950832

[50] Bloom S, Lippeveld T, Wypij D. Does antenatal care make a difference to safe delivery? A study in urban Uttar Pradesh, India. Health Policy Planning 1999; 14: 38-48. http://dx.doi.org/10.1093/heapol/14.1.38

[51] Showstack JA, Budetti PP, Minkler D. Factors associated with birth weight: An exploration of the roles of prenatal care and length of gestation. Am J Public Health 1984; 74: 10038. http://dx.doi.org/10.2105/AJPH.74.9.1003

[52] Ramakrishnan U, Neufeld L. Recent advances in nutrition and intrauterine growth. In: Martorell R, Haschke F, Eds. Nutrition and growth. Nestlé Nutrition Workshop Series. Vol
47. Philadelphia: Lippincott-Williams and Wilkins 2001; 97-121.

[53] Ramakrisnan U. Nutrition and low birth weight: from research to practice. Am J Clin Nutr 2004; 79: 17-21.

[54] Ramakrishnan U, Martorell R, Schroeder DG, Flores R. Intergenerational effects on linear growth. J Nutr 1999; 129 544-9.

[55] Martorell R, Ramakrishnan U, Schroeder DG, Melgar P Neufeld L. Intrauterine growth retardation, body size, body composition and physical performance in adolescence. Eur $\mathrm{J}$ Clin Nutr 1998; 52(Suppl): 43-53.

[56] Stein AD, Barnhart HX, Hickey M, Ramakrishnan U, Schroeder DG, Martorell M. Prospective study of proteinenergy supplementation early in life and growth in the subsequent generation in Guatemala. Am J Clin Nutr 2003; 78: 162-7. 